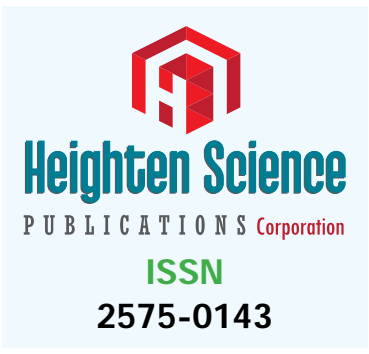

*Address for Correspondence: Prof. Dr. Med. Stefan Peters, Chief Cardiologist, AMEOS Hospital Halberstadt, Gleimstr 538820 Halberstadt, Germany, Email: H.u.S.Peters@t-online.de

Submitted: 22 December 2016

Approved: 29 December 2016

Published: 30 December 2016

Copyright: @ 2016 Peters. This is an open access article distributed under the Creative Commons Attribution License, which permits unrestricted use, distribution, and reproduction in any medium, provided the original work is properly cited.

Keywords: Takotsubo syndrome; Atherosclerotic coronary artery disease; Small LAD

\section{Mid-Ventricular Ballooning in Atherosclerotic and Non- Atherosclerotic Abnormalities of the Left Anterior Descending Coronary Artery}

\author{
Stefan Peters* \\ AMEOS Hospital Halberstadt, Germany
}

Myocardial coronary bridging [1], encasement [2], and mid-LAD rigid straightening [3-5] appears to be epiphenomenon of takotsubo syndrome [6], rather than causing the disease. Typical takotsubo syndrome usually lasts only a few weeks, but chronic takotsubo cardiomyopathy is reported [7].

In a series of meanwhile 10 cases rigid straightening of the mid-portion of the left anterior descending coronary artery without lumen reduction mid-ventricular or basal ballooning was reported, or both basal and mid-ventricular ballooning in one case [4]. In all these patients wrap-around (recurrent segment) phenomenon of the left anterior descending coronary artery was not present. The abnormalities of the left anterior descending coronary artery are due to myocardial bridging without lumen reduction of the LAD, only seen in computed tomography [3]. When stress or in some cases happiness appears myocardial ballooning can appear, lasts 2-4 weeks and disappear with a recurrence rate of nearly $10 \%$ despite beta blocking agents [8].

Here we report a case of typical mid-ventricular ballooning in an atherosclerotic high-grade lesion of a small left anterior descending coronary artery with normally contracting apical segment of the left ventricle. A 58-year old male patient suffered from chest pain and was submitted to a hospital without coronary angiography facilities. ECG was normal; troponin rise was relevant. The patient was transported into a hospital with the possibility of prompt coronary angiography.

Left ventricular and coronary angiography was done short after reaching the hospital with coronary angiography facilities.

Left ventricular angiography revealed typical mid-ventricular ballooning with a normal contracting apical segment. The very small left anterior descending coronary artery revealed a proximal high-grade stenotic lesion with insignificant abnormalities of the circumflex and right coronary artery. The high-grade stenosis war treated by PCI.

This case contradicts the opinion of relevant authors who did not see any case of mid-ventricular ballooning in atherosclerotic lesions. When mid-ventricular ballooning can be detected in atherosclerotic lesions of the very small LAD not reaching the apex it is discussable whether rigid straightening of the left anterior descending coronary 
artery of takotsuko syndrome is only an epiphenomenon, but not the cause of midventricular ballooning. Myocardial bridging without lumen reduction, only seen in computed tomography, can be the cause of sudden cardiac death or chronic form of takotsubo cardiomyopathy [9]. And it can be the cause of takotsubo syndrome if stress or happiness appears and a time-limiting contraction impairment of the left ventricle follows.

In general, myocardial bridging can appear as an anatomical variant in normal subjects, patients with coronary artery disease and other cardiac pathologies, and in patients with takotsubo syndrome [6].

\section{REFERENCES}

1. Stiermaier T, Desch S, Blazek S, Schuler G, Thiele H, et al. Frequency and significance of myocardial bridging and recurrent segment of the left anterior descending coronary artery in patients with takotsubo cardiomyopathy. Am J Cardiol. 2014; 114: 1204-1209. Ref.: https://goo.gl/Z1NCkc

2. Duchesne J, Hoffman I. Is LAD encasement a common substrate component in Takotsubo cardiomyopathy? J Electrocardiol. 2016; 49: 629-631. Ref.: https://goo.gl/b076m6

3. Migliore F, Maffei E, Perazzolo Marra M, Bilato C, Napodano M, et al. LAD coronary artery myocardial bridging and apical ballooning syndrome. J ACC Cardiovasc Imaging 2013; 6: 32-41. Ref.: https://goo.gl/XQiz] 9

4. Peters S. Identification of mid-ventricular ballooning takotsubo cardiomyopathy by pure coronary angiography. Int J Cardiol. 2016; 221: 697. Ref.: https://goo.gl/ql4w5U

5. Peters S. Mid-ventricular ballooning in takotsubo cardiomyopathy: from a concealed to a manifest form. Int J Cardiol. 2016; 223: 195-198. Ref.: https://goo.gl/duhPyв

6. Madias J E. Is the coronary artery myocardial bridging and left anterior descending straightening mediated by the myocardial wall motion abnormalities and edema in takotsubo syndrome? Int J Cardiol. 2016; 225: 18-19. Ref.: https://goo.gl/9yCR29

7. Madias J E. Recurrence, lingering recovery course, mild variants, and chronic forms, of takotsubo syndrome. Int J Cardiol. 2016; 220: 70-71. Ref.: https://goo.gl/qY4vjc

8. Sharkey SW, Maron BJ . Epidemiology and clinical profile of Takotsubo cardiomyopathy. Circ J. 2014; 78: 2119-2128. Ref.: https://goo.gl/zQMf5w

9. Peters S. Typical and atypical takotsubo cardiomyopathy - simply stress - induced or dependent of the left anterior descending coronary artery? Int J Cardiol. 2016; 223: 475-476. Ref.: https://goo.gl/FjgMxz 